\title{
Elementos para una antropología pneumática
}

\author{
Víctor Codina, S.J., \\ Universidad Católica Boliviana, \\ Centro de Espiritualidad Ignaciana, \\ Cochabamba, Bolivia
}

La antropología teológica se ha elaborado en los últimos años fundamentalmente desde la cristología. El presente texto ofrece algunos elementos para completar esta visión cristológica de la antropología con la perspectiva de la pneumatología, mostrando la dimensión humanizadora del Espíritu.

\section{Antropología teológica}

Una antropología teológica implica elaborar un pensamiento antropológico no simplemente filosófico o científico, sino desde la Palabra, la fe, la revelación y la tradición de la Iglesia. Este era el objeto del clásico tratado de Deo creante et elevante (de gratia), que ahora se llama Antropología teológica.

Teóricamente, una antropología teológica se puede desarrollar desde una triple clave teológica: desde el Dios creador, desde Cristo y desde el Espíritu. Veamos lo que implica cada una de estas perspectivas teológicas.

\subsection{Desde el Dios creador}

Muchas veces, en la teología ad usum anterior al Vaticano II, la antropología se inscribía en el marco de la creación de la nada (ex nihilo) y aparecía sin duda como obra del Dios Padre todopoderoso y omnipotente, pero ordinariamente reconociendo al Creador atributos más filosóficos que teológicos: el Dios uno, todopoderoso, que crea como causa primera incausada, el acto puro, el Ens a se, de lo cual se deduce la contingencia humana, ens ab alio, y la continua dependencia del Creador, con una religación causal y permanente.

La imagen de la creación de Adán en la conocida pintura de Miguel Ángel, de la Capilla Sixtina, puede simbolizar esta mentalidad filosófico-teológica: un 
hombre joven desnudo, tendido en la tierra, recién amanecido a la vida, gracias al dedo de un Dios todopoderoso y fuerte que se aleja de él y le deja solo y abandonado a su propia suerte. Este Dios parece ser una mónada solitaria, poderosa y lejana, que muchas veces produce en la criatura una sensación de impotencia que incluso puede desembocar en un rechazo y una autodivinización narcisista ${ }^{1}$.

Esta imagen, sin duda un poco simplista y casi caricaturesca de la antropología tradicional, es la que se ha transmitido muchas veces a la vida cristiana popular y a la espiritualidad, reflejando una visión más escolástica y filosófica que ligada a la Palabra de Dios.

Indudablemente, la antropología teológica actual es mucho más bíblica, y en ella el ser humano - hombre y mujer - aparece creado a imagen y semejanza de Dios y cobra vida bajo el soplo del aliento divino, de la ruah. De ahí radica su dignidad humana ${ }^{2}$. Esto ha llevado a desarrollar una teología de la imagen y semejanza, en sintonía con la patrística oriental, pero que quizás todavía es poco trinitaria, pues aparece más ligada al poder omnipotente del Dios Creador que al amor del Padre, que en el Hijo y el Espíritu comunica su vida y busca la comunión.

\subsection{En Cristo}

Por esto, la visión creacional clásica necesita ser completada con una visión más cristológica. Cristo es la verdadera imagen del Padre, hemos sido creados en Cristo, a imagen de Cristo (Col 1, 15), el verdadero pantokrátor que nos abraza en su amor comprehensivo, somos imagen de la imagen, desde Cristo conocemos al hombre, Cristo es el hombre en plenitud (¡ecce homo!). Antropología y cristología están estrechamente unidas, la antropología es una cristología deficiente y la cristología es origen fontanal y término de la antropología, el hombre es esbozo de Cristo, "el hombre es lo no-Dios que puede ser auto-exteriorización de Dios y posible hermano de Cristo", es "el otro modo de ser de Dios mismo"3.

De ahí se sigue el ideal de asemejarse a Cristo, de la imitación de Cristo (Kempis), del seguimiento de Jesús (Ejercicios Espirituales ignacianos), con el riesgo de un cierto moralismo voluntarista si no se completa pneumatológicamente. ¿Por qué seguimos a Jesús? Si no queremos caer en un jesuanismo

1. G. Greshake, Creer en el Dios uno y trino, Santander, 2002, pp. 109-114.

2. Ante la imposibilidad de presentar aquí el desarrollo de la antropología teológica moderna, nos limitaremos a recordar los tratados clásicos de Juan Luis Ruiz de la Peña: Teología de la creación, Santander, 1980; Las nuevas antropologías. Un reto a la teología, Santander, 1983, etc.

3. K. Rahner, "Reflexiones fundamentales sobre antropología y pro-teología en el marco de la teología", en Mysterium salutis, II-I, Madrid, 1969, pp. 464-466. 
corto, hemos de reconocer que seguimos a Jesús porque él nos comunica la vida divina, el Espíritu ${ }^{4}$.

La cristología de América Latina que define el cristianismo como "seguimiento de Jesús", con todo lo positivo y rico que tiene esta expresión concreta de la fe cristiana, ¿no tiene el peligro de desembocar en un cierto voluntarismo moralista si el seguimiento de Jesús no se integra en la gratuidad del don del Espíritu y la prioridad de la llamada? La cristología nos remite necesariamente a la pneumatología, sin pneumatología no hay cristología, ni vida cristiana, ni seguimiento de Jesús. Toda cristología debe ser pneumatológica, así como toda pneumatología debe ser cristológica.

Hoy día se pide la elaboración de una cristología espiritual, pneumatológica, que relacione a Cristo con el Espíritu ${ }^{5}$. La vida cristiana, como afirma Benedicto XVI en su primera encíclica, no nace de una decisión ética o una gran idea, sino del encuentro con una Persona, que nos da un nuevo horizonte y una orientación decisiva en la vida ${ }^{6}$. Este encuentro con Cristo es un encuentro espiritual, es el comienzo de una vida nueva en Cristo, por el Espíritu.

\subsection{En el Espíritu}

La misteriosa ruah que aparece desde Gn 1, 2, juntamente con la Palabra creada, aleteando y dando vida en medio del caos inicial, está también presente en la creación del hombre en el segundo relato yahvista de la creación $(\mathrm{Gn} 2,3)$. Aliento vital y Palabra están estrechamente unidos, como aparece en los salmos: "Por la Palabra de Yahvé fueron hechos los cielos, por el aliento de su boca todos sus ejércitos" (Sal 33, 6).

La ruah presente a lo largo de todo el $\mathrm{AT}^{7}$ significa, etimológicamente, aliento, viento, vitalidad, energía vital, ánimo, capacidad, aire en movimiento, que se manifiesta en respirar, a veces en jadear, en respirar fogosamente como en el parto. Su género femenino en hebreo posiblemente esté ligado a la capacidad de engendrar vida, mientras que cuando significa un viento huracanado destructor, es del género masculino ${ }^{8}$.

4. K. Rahner, Von der Geheimnis Gottes dem Menschen verstehen, München, 1984, pp. 105 y s.

5. Ya en 1979 la Comisión Teológica Internacional pedía la integración de cristología y pneumatología; tanto W. Kasper como H. U. von Balthasar intentaron responder a esta petición; cf. F. X. Durrwell, Jesus Fils de Dieu dans l'Esprit Saint, París, 1997, p. 75 , nota 1 .

6. Benedicto XVI, Deus caritas est, n. 1, 2005.

7. Presente 389 veces (D. Lys, Le souffle dans l'Ancien Testament, París, 1962, p. 334).

8. La Iglesia sirio-armenia desarrollará ampliamente esta dimensión femenina del Espíritu que aparece como madre que engendra vida. El Espíritu es la costilla del 
La ruah, con el tiempo, se interpretará como el Espíritu de Yahvé y el credo niceno-constantinopolitano, a partir de la doxología litúrgica eclesial (lex orandi, lex credendi), definirá el Espíritu como Señor, Kyrios (es decir, Espíritu de Dios, inmanipulable, 2 Cor 3, 17), dador de vida (es decir, vivificador, Jn 6, 63), que habló por los profetas (dimensión histórica del Espíritu, 2 Pe 1, 21) y que es glorificado juntamente con el Padre y el Hijo (doxología, aspecto de comunión, homotimía). Este Espíritu divino que habló por los profetas es el que suscitó en Israel personajes carismáticos y salvadores del pueblo, como los jueces, descansó sobre los reyes, con una unción mesiánica que anticipa al futuro Mesías ungido por el Espíritu (Is 11, 1-11)9.

Jesús será el portador del Espíritu, la salvación que Jesús nos trae se define como fruto del Espíritu y por esto, desde la pneumatología, el seguimiento de Jesús no se convierte en una mera imitación o compromiso por el Reino, sino en una "vida en Cristo", una vida "en el Espíritu", una vida "según el Espíritu", una nueva criatura nacida del Espíritu, que vive la filiación y puede llamar a Dios Abba-Padre. Esta vida nueva en Cristo implica una verdadera divinización, fruto de la autocomunicación de la vida de Dios (Selbsmitteilung), don escatológico del poder de Dios. En el Espíritu es como Dios se nos autocomunica, la salvación que ha surgido "extra nos", se hace, "pro me", como formularía Lutero.

Este Espíritu no es una fuerza anónima, es la forma de actuar del Señor exaltado, es distinto de Cristo, permanece en comunión trinitaria con el Padre y el Hijo (2 Cor 13, 13). Este Espíritu, invisible y anónimo, solo es experimentable por sus dones y frutos. Se ha dicho que no es "sustantivo", sino "verbo", es decir, dinamismo, vida, acción.

No se puede oponer divinización a humanización, como si la divinización nos deshumanizase y la humanización se constituyese al margen de, o en contra de, la filiación divina. La plenitud humana consiste en realizarse como imagen y semejanza de Dios, la gloria de Dios se manifiesta en la vida humana y esta vida humana se consuma y alcanza su plenitud en la comunión con Dios, por Cristo, en el Espíritu ${ }^{10}$.

\section{Diferentes pneumatologías configuran diversas antropologías}

Antes de intentar diseñar las líneas de una antropología pneumática o espiritual, hemos de clarificar las diferentes visiones teológicas sobre el Espíritu Santo existentes en la Iglesia.

Logos de la cual nace la Iglesia. Así como Eva es la madre que da vida, el Espíritu Santo (no María) es la madre de la vida nueva y la madre de la Iglesia; $c f$. B. J.

Hilberath, Pneumatología, Barcelona, 1996, p. 159.

9. X. Pikaza, Creo en el Espíritu Santo, Madrid, 2001, pp. 9-53.

10. Ireneo, Adv Haer IV, 20.5-7. 


\subsection{Filioquista}

En la postura típica de Juan, que la Iglesia latina ha desarrollado preferentemente, el Espíritu Santo procede del Padre y del Hijo. Este es el origen bíblico del clásico Filioque, que fue añadido al credo niceno-constantinopolitano por la Iglesia latina, lo cual produjo una reacción contraria en la Iglesia del Oriente, porque creía que el Espíritu quedaba postergado y excesivamente supeditado al Hijo, mientras que la paternidad del Padre quedaba disminuida, porque se afirmaba que el Espíritu procedía del Padre y del Hijo como de un único principio ${ }^{11}$.

En esta visión pnmeumatológica, la Palabra precede al Espíritu, el Espíritu es el don pascual del Resucitado (Jn 20), pues antes de su glorificación no había Espíritu (Jn 7, 39), el Hijo viene al mundo y se encarna para darnos el Espíritu, Jesús da el Espíritu sin medida (Jn 3, 34), este Espíritu será el otro paráclito (Jn 14, 16), que enseñará y recordará el mensaje de Jesús (Jn 14, 26), dará testimonio de él (Jn 15, 26), convencerá al mundo de la culpa (Jn 16, 7-11), llevará a los suyos a la verdad plena y glorificará al Hijo (Jn 16, 13-15). Según Juan, el espíritu que Jesús emite al morir en la cruz significa mucho más que la entrega de su aliento vital en la muerte (Jn 19, 30), representa el don del Espíritu pascual a la humanidad, que acontece cuando Jesús es elevado y exaltado en la cruz.

También Pablo, que no conoció al Jesús de Nazaret según la carne, sino que tuvo la experiencia del Cristo glorioso, presenta al Espíritu como el don del Resucitado y cuyos frutos se oponen a los frutos de la carne (Gal 5, 19-25) ${ }^{12}$.

Esta dimensión histórico-salvífica de Cristo como donador del Espíritu manifiesta claramente en su expresión de la Trinidad "ad extra" (la llamada Trinidad económica), la dimensión de la Trinidad "ad intra" (o Trinidad inmanente) ${ }^{13}$ : en la Trinidad inmanente, el Espíritu procede del Padre y del Hijo, es el lazo de comunión que une a ambos, es el amor trinitario, es la caridad, el don, la communio.

Esta visión, teológicamente correcta y plenamente ortodoxa, forma parte de la fe y de la tradición de la Iglesia y ha sido desarrollada ampliamente por Agustín, para quien el Hijo nace del Padre por el conocimiento, mientras que el Espíritu es el amor que une al Hijo con el Padre. Pero esta concepción teológica tiene el riesgo de desembocar en un encubierto cristomonismo (usando la expresión acuñada por Nikos Nissiotis) si no se complementa con otras visiones del Espíritu.

11. Para una mayor profundización del tema del Filioque, $c f$. V. Codina, Los caminos del Oriente cristiano, Santander, 1997, pp. 22-24; 91-98.

12. Véase B. J. Hilberath, Pneumatología, óp. cit., pp. 87-88.

13. Siguiendo la ya clásica afirmación de K. Rahner, $c f$. "Advertencias sobre el tratado 'de Trinitate"”, en Escritos de Teología, IV, Madrid, 1961, pp. 105-136. 
No es casual que Santo Tomás llegue a afirmar que es igual error negar el Filioque que cuestionar la autoridad del Vicario de Cristo sobre la Iglesia universal, pues en ambos casos el Espíritu está ligado al poder divino de Cristo, y el Vicario de Cristo es causa instrumental de la donación del Espíritu en la Iglesia $^{14}$. Esto conduce a un cierto eclesiocentrismo: la Iglesia, sobre todo la jerárquica que representa a Cristo, es la que posee el Espíritu y lo comunica a los fieles por la Palabra y los sacramentos. La Iglesia es un sistema cerrado, como una pirámide en cuyo ápice se encuentra, con la autoridad de Cristo, el Papa, quien en virtud de su plena potestas efectúa desde su posición central la unidad de la Iglesia: un Señor, un Cristo, un Papa ${ }^{15}$.

De ahí nace también una antropología teológica descendente, que ilumina la realidad humana desde Cristo, desde la fe se entiende al hombre, una antropología más bien estática, que parte de la luz de la fe para juzgar la realidad, sin antes haber agotado su conocimiento, que puede llevar a una visión poco respetuosa de la autonomía de la realidad. Desde América Latina diríamos que es una metodología del "juzgar" sin haber pasado por el "ver" de la Palabra, sin partir de la vida.

Una pneumatología sesgadamente filioquista puede generar una antropología más centrada en la sumisión a la jerarquía que abierta al profetismo del Espíritu que sopla donde quiere, más obediente que creativa y libre, más sumisa y discente que sujeto activo que, por la unción del Espíritu y su profundo sentido de la fe, acoge personalmente, intuye, es capaz de innovar y de ser un lugar teológico verdadero, junto a la Escritura y a la Tradición, en la línea del sensus fidelium de LG $12^{16}$.

Es una antropología más proclive a la unidad uniforme que a la alteridad, al pluralismo y a la riqueza de la diversidad, más individual que comunitaria, que se inclina también a una eclesiología fundada más en Lumen gentium que en Gaudium et Spes o Ad gentes.

Lo positivo de este enfoque joaneo-paulino es reconocer la dimensión cristológica, eclesial y sacramental de la gracia y del Espíritu, frente a toda tentación espiritualista, iluminista, entusiasta, subjetiva e intimista de la salvación. En lenguaje de Ireneo: la mano del Espíritu es inseparable de la mano del Hijo, ya que ambas manos crean al hombre y lo conducen a la koinonía ${ }^{17}$.

14. Contra errores graecorum, Opera omnia, ed. Parma, t. XV, p. 256.

15. G. Greshake, Creer en el Dios uno y trino, óp. cit., pp. 90-96.

16. Puede verse desarrollado este aspecto en V. Codina, ¡No extingáis el Espíritu! Una iniciación a la Pneumatología, Santander, 2008.

17. Adv Haer V, 6, 1; V 28.4. Cf. L. E. dos Santos Nogueira, O Espírito e o Verbo. As duas mâos do Pai, São Paulo, 1995. 
Esta postura filioquista recalca la dimensión encarnatoria, mediada, nazarena de la salvación, de la humanidad de Dios, como fruto de la presencia del Espíritu, lo cual es positivo, pero parece limitar otras dimensiones carismáticas y no institucionales de la Iglesia: el Espíritu llena el universo, desborda la Iglesia visible, actúa misteriosamente en quienes no son cristianos (GS 22) ni seguramente nunca lo serán.

\subsection{Spirituque}

Esta expresión, que algunos orientales como Paul Evdokimov ${ }^{18}$ proponen para compensar la unilateralidad del Filioque, afirma que no solo el Espíritu procede del Padre y del Hijo, sino que el Hijo nace del Padre en el Espíritu, Spirituque, el Espíritu está al comienzo y al final de la vida trinitaria, no es solo el tercero y último. Esta misma idea ha sido retomada por otros autores orientales como Bobrinskoy, Zizioulas, Staniloae y también por L. Boff. Siguiendo a Basilio, para quien el Espíritu es el Aliento de la boca de Dios (Sal 33, 6) que procede del Padre, se afirma que el Espíritu acompaña a la Palabra, descansa en la Palabra, manifiesta la Palabra ${ }^{19}$.

Esta es la línea seguida por los sinópticos y en especial por Lucas en su Evangelio y en los Hechos. El Espíritu es precursor de Cristo. Si Cristo resucitado puede comunicar el Espíritu, es porque él mismo ha sido generado y constituido pneumatológicamente en su concepción en el seno de María, en el bautismo, durante toda su vida y finalmente en su resurrección. Si Jesús es la mediación del Espíritu, es porque él mismo ha sido ungido por el Espíritu en el bautismo. Si en la sinagoga de Nazaret anuncia que ha venido a liberar a los cautivos y dar vista a los ciegos, es porque ha sido ungido por el Espíritu y, por esto, solamente después de su unción por el Espíritu comienza a predicar la buena nueva a los pobres (Lc 4, 14-21).

El Espíritu transformará algo brutal como la cruz en fuente de vida. Para Lucas hay un paralelismo entre el bautismo de Jesús y la venida del Espíritu en Pentecostés, que es el verdadero bautismo de la Iglesia. Como dirá Pedro ante Cornelio, Jesús de Nazaret, que pasó por el mundo haciendo el bien y curando a todos los oprimidos por el maligno, es el mismo que ha sido ungido por el Espíritu (Lc 10, 38).

Esta presencia y acción del Espíritu en Jesús es claramente afirmada por los padres de la Iglesia oriental, concretamente por Basilio: "La venida de Cristo: el Espíritu la precede. La encarnación: de ella es inseparable el Espíritu. Las acciones milagrosas, los carismas de curación: se dan por medio del Espíritu. El

18. P. Evdokimov, L'Esprit Saint dans la tradition orthodoxe, París, 1969, p. 78.

19. Véase D. Edwards, Aliento de vida, Estella, 2008, pp. 236-249. 
diablo es rechazado, ante la presencia del Espíritu. La redención de los pecados se da en la gracia del Espíritu"20.

La ruah que aleteaba en la creación sobre el caos, que da vida al hombre, que guía la historia de Israel, que habla por boca de los profetas, es el mismo Espíritu que hace nacer a Jesús de María Virgen, el que desciende sobre Jesús en el bautismo, el que guía toda la vida de Jesús en sus palabras y acciones, y es el Espíritu que le resucita de entre los muertos.

El Espíritu convierte a Jesús en un ser relacional, en comunión no solo evidentemente con el Padre (el Abba), sino con la humanidad, con los suyos, con su cuerpo eclesial, que es la Iglesia, cuyo corazón es la eucaristía. Por el Espíritu, Jesús asume una personalidad corporativa, para utilizar un término que ha sido ampliamente desarrollado por la teología bíblica. Y lo introduce también en comunión con el cosmos, ya que él es el alfa y omega de la creación, primogénito de la vida nueva de los resucitados (Ap 1, 17-18). Cristo es un ser relacional, el Adán que da vida, un hombre comunional y escatológico por el Espíritu (1 Cor 15, 45).

El Espíritu es quien hará nacer la Iglesia en Pentecostés, el que guía la historia de la humanidad (las culturas, las religiones, los movimientos sociales, los signos de los tiempos...), es el que produce en el ser humano la apertura al misterio, a la trascendencia, el llamado "existencial sobrenatural" es la huella del Espíritu en el ser humano. Sin Espíritu no hay creación, no hay encarnación, ni Iglesia, ni salvación, ni vida eterna, ni resurrección de la carne, ni Reino de Dios. Es más, podemos afirmar que expresiones como salvación (sotería), Reino de Dios (basileia), la autocomunicación de Dios (la rahneriana Selbstmitteilung), la gracia, el amor, el nuevo nacimiento, la filiación, la liberación del pecado y de la muerte, la comunión-koinonía, la divinización... no son más que formas diversas para expresar la presencia viva del Espíritu en nuestras vidas y en la historia.

Si conocemos la Trinidad inmanente a partir de la Trinidad económica, entonces es claro que la presencia del Espíritu, tanto en la encarnación como en el bautismo y en la resurrección de Jesús, nos está revelando que en el misterio intratrinitario de Dios el Hijo es generado no solo por el Padre, sino por el Padre y el Espíritu, Spirituque. En esta concepción, el Espíritu no es solo el vínculo de comunión entre el Padre y el Hijo, la "tercera" persona de la Trinidad, como afirma la tradición latina siguiendo sobre todo a Agustín; sino que el Espíritu se halla presente junto al Padre en la misma filiación eterna del Hijo, en la generación del Hijo, la cual no es únicamente fruto del conocimiento del Padre, sino del amor, del Espíritu. El Espíritu es el amor hipostasiado con el que el Padre engendra al Hijo. El aliento divino, la ruah, no solo está al término, sino al

20. Basilio, De Spiritu Sancto 16. 39. 
comienzo; la pneumatología no es posterior, sino coeterna y simultánea a la cristología. El Padre que engendra eternamente al Hijo por el Espíritu es quien resucita a Jesús por el mismo Espíritu (Rm 8, 11). Por el Espíritu, el Padre engendra al Hijo, engendramiento que alcanza su plenitud en la Pascua. El Padre engendra al Hijo por el amor y lo resucita por el amor, es decir en el Espíritu: "Tú eres mi Hijo, yo te he engendrado hoy" (Hch 13, 33; cf. Sal 2, 7) ${ }^{21}$.

Esta visión de la Trinidad puede despertar sospechas o turbación en algunos, acostumbrados al orden (taxis) Padre, Hijo y Espíritu Santo. El Espíritu no es el origen, pues esto corresponde al Padre, pero tampoco el término final. El Espíritu está al comienzo y al fin, es coeterno, no es estéril, es la fecundidad amorosa de Dios, por esto recibe el mismo honor y gloria que el Padre y el Hijo. El Padre habla, el Hijo es la Palabra, pero el Espíritu es el aliento vital, el soplo que hace audible la Palabra. El orden Padre-Espíritu-Hijo no es desconocido en la Escritura (Ap 1, 4s) ni en la tradición ${ }^{22}$.

Así se puede dar una perfecta interrelación y pericoresis entre el Padre, el Hijo y el Espíritu, sin relegar al Espíritu a un tercer lugar, sino mostrando que ambos, las dos manos del Padre, en él tienen su origen, tienen igual dignidad divina en medio de la diferencia personal de cada uno: el Hijo engendrado por el Padre en el Espíritu se entrega amorosamente al Padre en el Espíritu que procede de ambos. El Espíritu está al comienzo y al final de la vida de comunión trinitaria, entendiendo comienzo y fin no en términos cronológicos, sino de eternidad misteriosa. El Espíritu es en persona el poder amoroso por el cual el Padre engendra al Hijo y el Hijo se entrega amorosamente al Padre en el misterio pascual. El Espíritu dice relación a la paternidad del Padre y a la filiación del Hijo, es Espíritu del Padre y del Hijo ${ }^{23}$.

En esta visión teológica, el Espíritu en algún sentido misterioso precede a la Palabra, el Espíritu es fuente de la cristología. En palabras técnicas y un tanto escolásticas de Rahner, el Espíritu es causa eficiente del hecho crístico, pero Cristo es la causa final de la acción del Espíritu ${ }^{24}$. En este sentido, toda cristología es pneumatológica, pues Jesús de Nazaret es el ungido por el Espíritu, constituido así Mesías y Cristo. Es el profeta escatológico henchido por el Espíritu, donde se realiza lo anunciado por el Siervo de Yahvé. Cristo es un ser pneumático, comunional y relacional, su personalidad es corporativa, será el nuevo Adán.

21. F. X. Durrwell, El Espíritu del Padre y del Hijo, Madrid, 1990.

22. B. Brobinskoy, Le Mystère de la Trinité, París, 1975, p. 78, afirma que la Iglesia siempre ha oscilado entre el esquema Padre-Hijo-Espíritu y el esquema Padre-Espíritu-Hijo.

23. F. X. Durrwell, Jesus Fils de Dieu dans l'Esprit Saint, París, 1997, pp. 90-102.

24. K. Rahner, Curso fundamental sobre la fe, Barcelona, 1979, pp. 369-371. 
Esta pneumatología que precede a la cristología nos lleva a una antropología ascendente, abierta, dinámica, que parte de la realidad de abajo, humana e histórica, que está movida e inspirada por el Espíritu, anteriormente al acceso a la Palabra. Es una perspectiva más misionera, más aristotélica que platónica, que respeta la autonomía de la creación, en la que la razón se abre a la fe, una visión más ligada a Gaudium et Spes (y a Ad Gentes) que a Lumen gentium, que concede una cierta prioridad a la comunidad o Iglesia local sobre la Iglesia universal ${ }^{25}$.

Pero el riesgo de esta postura, si no se complementa debidamente con la anterior, es caer en un pneumatocentrismo, en un espiritualismo desencarnado, en un pneuma más hegeliano que evangélico, olvidando que el Espíritu tiene una estructura cristológica como origen y fin, que el Espíritu es el Espíritu de Jesús y consiguientemente posee un estilo y modo nazareno, kenótico. El Espíritu prolonga en la humanidad los rasgos de Jesús de Nazaret, su cercanía a los pobres y pecadores, su oración al Padre, su confianza filial, su solidaridad y compasión ante el sufrimiento hasta estremecerse en sus entrañas (splajnizomai), la cruz, el Reino...

Por esto, ambas perspectivas, la sinóptica y la joaneo-paulina, la del Filioque y la lucana del Spirituque, no deben contraponerse, sino complementarse dialécticamente: el Padre engendra al Hijo en el Espíritu (el Espíritu es el seno o útero de Dios Padre ${ }^{26}$ ) y el Hijo en comunión amorosa con el Padre emite el Espíritu. Hay pericoresis, comunión, inter-comprenetración, circumincesión. Así, el Espíritu siempre será el Espíritu de Jesús, las dos manos del Padre son inseparables, filiación y procesión coexisten eternamente, en igualdad y reciprocidad mutua de comunión, la Fuente última es el Padre, cuya esencia paternal es engendrar infinitamente al Hijo infinito, en el Espíritu ${ }^{27}$.

25. Con motivo de la publicación de Communionis notio por la Congregación de la Fe (1992), en la cual se afirma que la Iglesia universal antecede ontológica y cronológicamente a la Iglesia local, surgió una fuerte polémica entre J. Ratzinger y W. Kasper, quien defendía la prioridad de la Iglesia local sobre la universal. Aunque al final llegaron a un cierto acuerdo al reconocer que hay una mutua inclusión entre ambas Iglesias, los acentos son diferentes, más ideológico (platónico) en Ratzinger y más realista (aristotélico) en Kasper, todo lo cual repercute en la forma concreta de gobernar la Iglesia. Cf. J. Martínez Gordo, "Eclesiología y gobernación. Debate de J. Ratzinger y W. Kasper sobre la relación entre la Iglesia universal y la iglesia local", Revista Latinoamericana de Teología 66 (2005), pp. 229-250.

26. Concilio de Toledo XI, en 675, "De patris utero, id est de substantia eius, idem Filus genitus vel natus" (DS 526), citado por F. X. Durrwell, Nuestro Padre, Salamanca, 1990, p. 142, nota 31.

27. F. X. Durrwell, Jesús Fils de Dieu dans l'Esprit Saint, óp. cit., p. 113, cita un texto del Maestro Eckhart: "La aspiración suprema de Dios es engendrar" ("Gottes höchstes streben ist gebären”), Sermo 11, Impletum est tempus Elisabeth. 
Consiguientemente, la antropología descendente filioquista se debe complementar con la antropología ascendente spirituquista e integrarse en una comunión pericorética de amor y de vida, en una especie de danza recíproca y armoniosa de diferentes unidos por el amor.

Hay una doble relación de Jesús con Dios: la relación descendente por la cual el Padre le proclama su Hijo (en la encarnación, el bautismo-transfiguración y la resurrección) y la relación ascendente por la cual Jesús en Espíritu llama a Dios Abba-Padre, sobre todo desde el misterio pascual. La primera relación corresponde a la acción del Espíritu en la filiación del Hijo por el Padre (Spirituque), la segunda a la comunión entre el Hijo y el Padre en el amor (Filioque). Ambas son inseparables.

\section{Rasgos de una antropología pneumática}

En el cuadro de Miguel Ángel de la Capilla Sixtina sobre la creación de Adán, solo aparece la figura del Padre que con su dedo extendido da vida al nuevo ser humano. No aparece la presencia vivificadora del Espíritu, a no ser que este "dedo de Dios" que se acerca a Adán recién creado significara el Espíritu (Mt 12, 28). Sea como fuere, es claro que la antropología teológica solo puede desarrollarse coherentemente desde el ángulo de una cristología que asuma la pneumatología, es decir, desde una cristología pneumatológica y desde una pneumatología cristológica.

Digamos que esta visión teológica de la antropología, concretamente pneumática o espiritual, no anula ni prescinde de la realidad antropológica humana, filosófica y racional, sino que la presupone y parte de ella, pues la gracia presupone la naturaleza, en expresión tomista clásica. Tampoco quiere favorecer una pasividad antropológica que espere todo del Espíritu, pues, como dicen los Padres de la Iglesia, "Dios trabaja, pero el hombre suda". Más bien, invita a una "sinergia", a una actitud responsable y libre de las personas que acogen el don del Espíritu de forma creativa. Pero una antropología teológica tiene elementos que claramente provienen de la fe en la Iglesia y que iluminan el ser y el actuar humano.

Para clarificar nuestro proceso, resumiremos lo que ya hemos insinuando en unas diez tesis fundamentales, una especie de decálogo para una antropología pneumática, aunque es muy difícil deslindar aspectos que están íntimamente implicados.

\subsection{El Espíritu es el Espíritu creador de nuestra vida humana}

El himno medieval Veni Creator Spiritus presupone algo que reconocen la teología (y la misma ciencia de hoy): la hominización es fruto de un largo proceso cósmico, de una lenta y millonaria evolución de la vida. Para la tradi- 
ción judeocristiana, al comienzo de esta lentísima explosión de vida en nuestro cosmos está la ruah, el Espíritu divino (Gn 1, 2) 28 .

Pero la Escritura no solo habla de la ruah que aletea sobre el caos primitivo, sino que mientras en el primer relato de la creación se dice que Yahvé crea al hombre a su imagen, varón y mujer (Gn 1,27), en el segundo relato de la creación se concreta diciendo que Yahvé sopla sobre el Adán formado de la tierra y le confiere vida (Gn 2, 7), una vida en comunión varón-mujer (Gn 2, 18-19), de modo que en la creación humana actúa el Espíritu, que es el dador de vida, de toda vida.

El Espíritu se manifiesta en la dualidad hombre-mujer, es decir, frente a una visión antropológica predominantemente machista que ha operado en la sociedad y en la Iglesia, el Espíritu es Espíritu de la alteridad y pide respetar las diferencias de género, sexuales, afectivas, psicológicas y espirituales existentes entre el varón y la mujer.

Más aún, hoy día muchos teólogos, y sobre todo teólogas, acentúan la dimensión femenina de la ruah, del Espíritu, en estrecha conexión con la Sabiduría y que se manifiesta con rasgos femeninos como fecundidad, ternura, bondad, acogida, respeto a la vida, interioridad, etc. En algunos iconos de la Trinidad, como el de Rublev, el Espíritu tiene rasgos femeninos y con su mano maternal parece engendrar y acoger la vida.

En todo caso, el Espíritu nos obliga a elaborar una antropología con dimensiones no exclusivamente patriarcales y a repensar muchos conceptos filosóficos y teológicos de la persona humana que no se identifican simplemente con el varón. Pensemos en las consecuencias que se derivan de esta antropología dualista para la misma teología, para la eclesiología, mariología, moral, espiritualidad, hermenéutica bíblica, liturgia, sacramentología, escatología, etc. Una teología elaborada durante siglos exclusivamente por varones necesariamente ha deformado, limitado y empobrecido la Palabra de Dios y el pensamiento teológico.

El rechazo y alejamiento actual de la Iglesia por parte de muchas mujeres cristianas está muy ligado a esta antropología patriarcal y a sus consecuencias teológicas, eclesiales, morales, espirituales, etc. Y, al revés, una lectura de la realidad antropológica y teológica "con ojos de mujer" nos está abriendo la mirada a muchas realidades nuevas que hasta ahora los varones desconocíamos.

28. D. Edwards, Aliento de vida. Una teología del Espíritu creador, Estella, 2008, pp. 65-90. 


\subsection{El Espíritu integra el dualismo cuerpo/alma}

El Espíritu une al ser humano, superando todo dualismo (cuerpo/alma, corporal/espiritual), de modo que tanto la dimensión de basar (que le une a la realidad de su pueblo y a los demás seres humanos) como el nefes (su dimensión de apertura y tendencial) están trascendidas y unificadas por la ruah $^{29}$.

Esta integración entre lo corporal y lo espiritual, fruto del Espíritu, nos lleva a evitar la construcción de una antropología dualista, más helénica que bíblica. Esto implica asumir en la antropología las dimensiones de la "carne" con todas sus consecuencias. La célebre frase de Tertuliano, "caro, cardo salutis", la carne como quicio de la salvación, tiene consecuencias no solo cristológicas, eclesiológicas y sacramentales, sino también antropológicas.

En la Iglesia ha predominado a lo largo de los siglos una visión muy pesimista sobre el cuerpo, la sexualidad, el matrimonio, con muchas consecuencias negativas, tanto espirituales como morales. Podemos preguntarnos si el haber ligado obligatoriamente el celibato al ministerio sacerdotal en la Iglesia latina no está influenciado por un cierto dualismo antropológico que une la sexualidad con impureza y alejamiento de Dios. Para muchos cristianos la visión helénica de la inmortalidad del alma prevalece sobre la idea bíblica de la resurrección de la carne, que nace de la Pascua de Jesús y que el credo une estrechamente a la fe en el Espíritu Santo: "Creo en la resurrección de la carne". La dimensión del cuerpo espiritual de Jesús resucitado (1 Cor 15, 45) se ha olvidado con frecuencia, lo cual no ayuda a una espiritualidad que intente anticipar ya ahora una transfiguración, aunque sea parcial, del cuerpo y de los sentidos, y una espiritualización de la corporalidad humana.

\subsection{El Espíritu nos hace personas}

El ser humano no solo es un individuo de naturaleza biológica destinado a la muerte (Sein zum Tode), sino que el Espíritu nos ofrece la posibilidad de entrar en comunión con la vida divina, de participar de una vida (no solo bios, sino zoé) que no acaba nunca. Esta orientación hacia la vida divina, marcada en la misma contingencia humana, es fruto del Espíritu que abre nuestra existencia a "algo" que nos supera y que es don gratuito. El "existencial sobrenatural" rahneriano es la huella ontológica del Espíritu en nuestro pobre ser creatural. El Espíritu es apertura a la trascendencia, nos despierta a las dimensiones más profundas de la existencia humana que no vive solo de pan, sino que tiene sed del Dios vivo, como la cierva que busca las fuentes de agua.

29. F. P. Fiorenza y J. B. Metz, "El hombre como unidad de cuerpo y alma", en Mysterium salutis, II-II, Madrid, 1969, p. 669. 
Más concretamente, el Espíritu, que es el dinamismo personal de comunión en la Trinidad, es quien nos hace personas y nos introduce en la comunión, nos hace seres en relación, nos abre a una posibilidad de comunión divina, humana y cósmica. Ser persona es "ser en relación", permanecer abiertos a la comunión con el Padre por Cristo en el Espíritu, abiertos a la comunión con los demás y a la comunión con la historia y el cosmos. No somos simplemente individuos que participamos de una misma naturaleza humana destinada a la muerte, somos personas, a imagen de la Trinidad, por el Espíritu de comunión. La persona no se concibe en sí misma como autoexistencia, sino como apertura extática a la comunión.

Y precisamente porque el Espíritu nos posibilita la apertura al misterio absoluto del Padre, por esto mismo el ser humano es una persona misteriosa, apofática, cuyo núcleo último ontológico de dignidad, de libertad y de creatividad lo hace sujeto de derechos humanos, alguien invulnerable y respetable, nunca manipulable, no es una máscara (en griego prosopon), sino una persona (hipóstasis), que participa y refleja aunque sea analógica y débilmente el misterio personal de la Trinidad que los primeros concilios definieron ${ }^{30}$.

Pero el Espíritu, además de hacernos personas, nos hace personas diferentes. El Espíritu, desde la creación a Pentecostés, es Espíritu de la pluralidad, de la diversidad, de la alteridad, una pluralidad que no es Babel ni confusión (Gn 11), sino, como en Pentecostés, comunión en la diversidad: cada cual escuchaba la predicación de Pedro en su propia lengua (Hch 2, 1-36).

En un mundo donde la diversidad cultural, racial y religiosa se ha convertido en oposición, conflicto y motivo de violencia, una antropología del Espíritu nos ayuda a ver la diversidad como riqueza, como complementariedad, como don del Espíritu vivificante, pálido reflejo de la pluralidad de personas en la Trinidad, donde hay alteridad y diversidad de personas en comunión.

\subsection{El Espíritu nos hace libres}

El Espíritu nos hace personas libres, está estrechamente ligado a la libertad, libertad antropológica fundamental, ya que Dios ha querido dejar al ser humano en manos de su propia decisión (Ecl 15, 14). La persona actúa según su propia conciencia y libre elección, por convicción interna y personal, no bajo coacción de un ciego impulso interior o exterior (GS 17).

De ahí nace la grandeza y tragedia humana, porque somos capaces de obrar el bien y de apartarnos de él. De aquí emana la posibilidad de la santidad y del pecado. Es el Espíritu el que nos hace libres y nos impulsa desde dentro a que actuemos según el proyecto de Dios, refuerza nuestra débil voluntad, nos inspira,

30. J. D. Zizioulas, Comunión y alteridad. Persona e Iglesia, Salamanca, 2009. 
anima, ilumina. Los clásicos siete dones del Espíritu que la teología espiritual ha desarrollado a partir de Is 11 no son más que ayudas del Espíritu a nuestra libertad. El Espíritu nos libera de la ley, nos hace libres interiormente, nos libera de la esclavitud del pecado y de la muerte, como Pablo recalca continuamente ( $\mathrm{Rm} 8,2 ; 3,27)$, ya que para la libertad hemos sido liberados (Gal 5, 1). La tradicional doctrina de la discreción de espíritus es una invitación a que sepamos actuar según el Espíritu y no nos dejemos engañar por todo lo que lleva a la muerte (Gal 5, 18-25).

El Espíritu hace, pues, al ser humano un ser libre, autónomo, responsable, capaz de actuar según su conciencia, pues es Espíritu de libertad (2 Cor 3, 17), libertad no solo para elegir cosas, sino para configurarse con Cristo, vivir en él, revestirse de él, ser su imagen viva y testimonial en el mundo.

Esta libertad radical que nos comunica el Espíritu se profundizará y hallará su expresión simbólica, sacramental y eclesial, cuando por la fe y el bautismo podamos dejar de ser esclavos del pecado y llamar a Dios Abba, Padre (Gal 4, 6; $\operatorname{Rm} 8,15)$.

\subsection{El Espíritu nos abre a la comunión humana}

Pero, además, como ya hemos insinuado antes, el Espíritu nos hace capaces de relacionarnos con otros(as), con personas diferentes. La persona es comunión interhumana, el yo se abre al tú, a los demás hermanos y hermanas, formamos con ellos una personalidad corporativa, con profundas raíces bíblicas. El Espíritu nos capacita para amar y entrar en comunión humana, nos abre a la fraternidad, a la solidaridad. Cuando Pablo VI reconoció que el ideal de la Revolución francesa, "libertad, igualdad y fraternidad", a pesar de todas sus ambigüedades y excesos cometidos, era profundamente evangélico, en el fondo reconocía que el Espíritu estaba impulsando aquellos ideales profundamente humanos.

El Espíritu convierte nuestra existencia humana de individual a personal y de personal a comunional y relacional, una existencia en comunión y en simpatía solidaria con todos, especialmente con los que sufren. El Espíritu crea personas en comunión, no individuos. En este sentido, la acción del Espíritu es personalizadora, relacional y comunional. El ser existe en relación, en comunión, nada es individual, sino personal, la persona existe en comunión, una comunión que no puede negar a la persona, pero que se abre a la alteridad, como sucede en la comunión trinitaria.

\subsection{El Espíritu nos abre a la comunión con toda la creación}

La creación humana, como ya hemos visto, se inscribe al final de un proceso cósmico de millones de años, de una larga evolución de energía, de hidrógeno y helio, de átomos, de galaxias y estrellas, de protozoos, del florecimiento de vege- 
tales y animales, que culminará en la aparición de los seres humanos. Toda esta evolución está suscitada por la ruah inicial, por el Espíritu que llena el universo (Sab 1,7), que es como la mujer que engendra la vida ${ }^{31}$.

Una interpretación sesgada y errónea de Gn 1, 28 ha llevado a la conclusión que el ser humano puede dominar y enseñorearse de la tierra, lo que ha conducido al abuso y explotación del universo y al desastre ecológico que padecemos actualmente. Una recta exégesis del texto bíblico (kabash) nos ofrece una versión diferente: a la persona humana le corresponde habitar la tierra, guardarla y cultivarla ( $c f$. Gn 2), respetarla, hacerla habitable. La tierra es de Dios (Lv 25, 23), el ser humano ha de respetarla (Sal 113; 8). Ha sido el individualismo moderno e ilustrado de Occidente, la ideología del progreso material indefinido y de la explotación mercantilista de la tierra con fines de lucro, lo que ha corrompido y pervertido esta visión primigenia de la tierra como sacramento de Dios, con la cual hemos de estar en relación de comunión, no de explotación ${ }^{32}$.

Aquí entra en juego la actualmente debatida cuestión del antropocentrismo o del cosmocentrismo. No queremos entrar en un juego de palabras, pues todo depende de qué se entienda por un término u otro. Tampoco podemos olvidar que toda la creación ha sido fundada en Cristo $(\mathrm{Col} 1,15)$ y que tiene una orientación cristocéntrica, pues Jesús es el alfa y omega (Ap 1,8).

Lo que es cierto es que no se puede seguir afirmando que "el hombre es el rey de la creación", que por tanto puede usar y abusar de ella a su antojo, sino que ha de vivir en una estrecha comunión solidaria con la tierra y con toda la creación, de la cual forma parte, debe escuchar su grito y gemido por haber sido esclavizada, que en el fondo es el grito del Espíritu creador que pide que la tierra sea liberada de la esclavitud a la que la hemos sometido ( $R \mathrm{~m} 8,20-25)$.

Desde este punto de vista, los movimientos ecológicos, en la medida que nos llaman a este respeto a la tierra y a sentirnos solidarios y parte de ella, están suscitados por el Espíritu, aunque a veces en ellos se pueda mezclar el trigo con la cizaña de ideologías o místicas extrañas a la fe cristiana.

\subsection{El Espíritu nos posibilita nacer de nuevo}

El ser humano no solo es débil, frágil, contingente, abocado a la muerte, precario, capaz de pecar, de apartarse de la comunión y de idolatrar a otros seres creados que finalmente se convierten en dioses asesinos que llevan a la muerte, sino que también es capaz de convertirse, ser recreado y nacer de nuevo por el

31. D. Edwards, Aliento de vida, óp. cit.

32. J. Carrera y J. I. González Faus, Horizonte Kyoto. El problema ecológico, Cuadernos de Cristianisme i Justícia, n. ${ }^{\circ}$ 133, Barcelona, 2005. 
Espíritu. Somos humanos al abrirnos al misterio, pero esta apertura es por el Espíritu, como Jesús es humano por abrirse totalmente al Espíritu.

Esta misteriosa apertura al Espíritu, accesible a toda la humanidad por el designio salvífico universal de Dios, que ha hecho de la Pascua de Jesús el baptisterio universal de la humanidad, acontece sacramentalmente en el bautismo cristiano (Jn 3, 3-8), donde se revela por la fe lo que sucede en todo ser humano que se abre al Espíritu de Dios.

El bautismo nos hace pasar sacramentalmente del ser biológico individual, destinado a la muerte, al ser personal, con identidad comunional, y todo ello por el Pneuma; nuestra vida pasa de bios a zoé. Por esto, el bautismo es un nuevo nacimiento, pues el primer nacimiento nos destina a la muerte, pero el bautismo por el Espíritu nos inserta en el Hijo de Dios y nos hace entrar en comunión con los hermanos en la Iglesia y la historia. La existencia humana por el bautismo es una existencia pneumática de comunión, la persona humana se vuelve "ser eclesial", se convierte en persona escatológica y orientada a la eucaristía, a la koinonía $(2$ Cor 13,13$)$ y a la escatología.

La unción de Jesús por el Espíritu en el bautismo se prolonga en nuestra unción y por esto podemos llamar a Dios Abba (Gal 4, 6; Rm 8, 15). La existencia personal pneumática es una existencia de filiación, de participación en el misterio del Hijo, por el Espíritu. Somos hijos del Padre en el Hijo, por el Espíritu de vida y de comunión que une al Padre y al Hijo.

\subsection{El Espíritu nos abre a la comunión eclesial}

Los bautizados en Cristo devenimos seres en comunión eclesial, la persona bautizada es un ser eclesial, un ser en relación con la comunidad nacida de la fe y del bautismo, una comunidad que nació en Pentecostés y que prosigue en la historia el camino de Jesús de Nazaret, su anuncio del Reino, su Evangelio, su poder de perdonar y de liberar del mal, su esperanza de una vida sin fin, en comunión con la vida del Espíritu de Jesús. La existencia humana, que por el bautismo es una experiencia pneumática de comunión, se vuelve hipóstasis eclesial orientada a la escatología a través de la eucaristía, que es fármaco de inmortalidad (Ignacio de Antioquía).

Desde esta óptica, la pertenencia a la Iglesia no es meramente jurídica o sociológica, sino una exigencia de comunión que nace del mismo ser persona en Cristo y del Espíritu que nos convoca a la comunión. Por esto, el centro de la Iglesia es un acontecimiento de comunión, la eucaristía, fruto de la invocación del Espíritu en memoria de la Pascua de Jesús ${ }^{33}$.

33. J. D. Zizioulas, El ser eclesial, persona, comunión, Iglesia, Salamanca, 2003, pp. 197-223. 
Dentro de esta apertura del Espíritu a la comunidad eclesial debería colocarse la cuestión de la renovación carismática católica y del pentecostalismo evangélico. Se trata de un fenómeno amplio, nuevo y complejo, que hay que discernir, pues si por una parte puede derivar en alienación y sentimentalismo afectivo y no oblativo, en show y psicología de masas que busca una compensación individual a un mundo materialista y cruel, por otra parte puede ser expresión de la fe de los pobres, de las mujeres, de los marginados, que recuperan su palabra en la Iglesia y que experimentan positivamente la acción del Espíritu en su conversión a una vida nueva, abandonando adicciones y abusos, sintiendo la alegría de conocer la Palabra y de sentirse miembros de una comunidad acogedora y festiva, muy diferente del doctrinarismo frío y moralizante de muchas Iglesias históricas. Los más pobres en América Latina acuden no a las comunidades de base, sino a los pentecostales ${ }^{34}$.

La pregunta es si este descubrimiento entusiasta y a veces un tanto salvaje del Espíritu no se deberá en parte al olvido que las Iglesias occidentales históricas han tenido del pneuma.

\subsection{El Espíritu nos abre a la comunión con la historia}

El Espíritu transfigura no solo la persona humana, sino la creación y la sociedad, en la línea del Reino, nos compromete a entrar en una relación con la historia y con toda la creación, de la que formamos parte desde la ruah primitiva.

El cristiano que sigue a Cristo por la fuerza del Espíritu prolonga la vida de Cristo en él y en la sociedad. El Espíritu que ungió a Jesús en el bautismo, que le llevó a anunciar la buena nueva a los pobres y guió toda su vida es el mismo que impele a la persona a configurarse con Cristo y, como él, pasar por el mundo haciendo el bien (Hch 10, 38).

Desde esta óptica, el Espíritu es un llamado a construir la comunidad humana en un mundo justo y fraterno, que respete la tierra y toda la creación como obra del Espíritu creador. Nos invita a discernir los signos de los tiempos (GS 4; 11; 44), a penetrar la realidad con una mirada no superficial, ni meramente sociológica o política, sino a ver la acción dinamizadora del Espíritu en los acontecimientos de la historia, a avanzar hacia el Reino de Dios, en comunión con todos los hombres y mujeres de buena voluntad, con todas las culturas y religiones, con la ciencia y las artes, que son todas ellas fruto de la acción creadora y salvífica del Espíritu que, de modo para nosotros misterioso, extiende la salvación del misterio pascual a toda la humanidad (GS 22).

34. El tema del pentecostalismo en América Latina ha sido muy estudiado desde la sociología religiosa que constata que pentecostalismo e islam son las religiones que más crecen en el mundo actualmente. Cf. Perspectiva teológica, número 119, eneroabril de 2011, Onda Pentecostal. 
Es necesario un discernimiento de los signos de los tiempos en la historia, reconociendo que el Espíritu actúa desde abajo, desde la debilidad de la carne, muchas veces en medio de la opacidad del pecado. Querer ver una acción pura y transparente del Espíritu en la historia (y también en la misma Iglesia) es ilusión, pues el Espíritu, a diferencia del Hijo, no se encarna en nadie. Habrá que ver si estos signos históricos están en sintonía con la vida de Jesús de Nazaret: kénosis, diakonia, koinonía, alegría, lucidez, autoestima, reconocimiento del otro, justicia, transfiguración de la realidad, consolación no solo personal, sino comunitaria, sobre todo en aquellos que viven en la exclusión y están condenados cada día a la muerte.

Finalmente, así como existe una verdadera historia del Espíritu en la vida de Jesús (concepción, bautismo, tentaciones, muerte, resurrección, exaltación, Pentecostés), también sucede lo mismo en nuestra historia personal y en la historia de la humanidad. Por esto necesitamos invocarlo continuamente y discernirlo ${ }^{35}$. Según algunos códices antiguos, en el Padre nuestro, en vez de "venga a nosotros tu Reino" se decía "venga a nosotros tu Espíritu".

\subsection{En un mundo abocado al caos y la muerte, el Espíritu es fuente de vida y esperanza}

Todo lo anterior podría resultar excesivamente idealista y romántico si dejamos de lado las dimensiones negativas de nuestra libertad y de la misma creación. Hay pecado personal y social, hay violaciones, violencia, guerras, injusticias, hambres, genocidios, sufrimientos sin fin, enfermedades. Existen terremotos, tsunamis, huracanes y sequías, en fin, estamos abocados al caos y a la muerte. Toda la creación, y nosotros con ella, gemimos con dolores de parto, esperando la liberación definitiva ( $\operatorname{Rm~8,~22-23).~}$

Frente a esta realidad, el Espíritu de vida se convierte en un principio humanizador y esperanzador en cuanto nos ofrece perdón y reconciliación en Cristo, nos abre a una esperanza de una vida que vence a la muerte no por el dinamismo natural biológico de la naturaleza o de la historia, sino por gracia de la resurrección de Jesús y del Espíritu pascual que es capaz de hacer pasar del pecado a la reconciliación, de la muerte a la vida, una vida sin fin, en comunión con el Señor. A través de nuestro gemido y del de la creación, es el Espíritu el que gime ( $\operatorname{Rm} 8,5-23)$.

El Espíritu nos mueve a "vivir bien", para usar un término de las cosmovisiones andinas y amazónicas, que significa vivir en armonía con la naturaleza y con los demás, no pretender "vivir mejor", lo cual significa abusar de la creación

35. Y. Congar, El Espíritu Santo, Barcelona, 1983, pp. 701-702. 
y excluir a los demás en provecho propio, como acontece en la economía individualista y consumista del mercado.

Jesús es el que expulsa a los demonios con el Espíritu de Dios, lo cual significa que el Reino llega (Mt 12,28). Hay una confrontación duélica entre el Reino que Jesús inaugura y el poder maligno del pecado y de la muerte. Por esto la oración que pedía "venga tu Espíritu" acababa pidiendo "libéranos del Maligno".

El Espíritu, por ser don de vida y de comunión, es don escatológico que inaugura los tiempos futuros (Hch 2, 17-18) y nos ofrece la esperanza de que el dolor, el caos y la muerte puedan engendrar un kairós de vida sin fin. El Espíritu que resucitó a Jesús de entre los muertos es el que nos resucitará a nosotros también (Rm 8, 11). Si Cristo nos salva de algo, es de la muerte, entendida esta como la vuelta al no-ser ${ }^{36}$.

Por esto en Pentecostés se cita el texto de Joel en el que se profetiza que los viejos tendrán sueños y los jóvenes, visiones (Hch 2, 17-21), es decir, el Espíritu nos abre a la esperanza del futuro, nos hace vivir con ilusión en medio de la precariedad de la vida y los desastres de la historia. El Espíritu es el auténtico "principio esperanza", que postulan filósofos humanistas como Ernst Bloch.

El Espíritu nos libera, pues, del mayor temor humano, del temor a la muerte, muerte espiritual y física, un miedo que no es solamente psicológico, sino ontológico, el miedo a no-ser. El Espíritu nos promete la resurrección de la carne y la vida, una vida sin ocaso, en la comunión de los santos, en la comunión trinitaria, misterio de vida, de amor y de gozo.

El Espíritu inaugura la llegada del éschaton en la historia y, en este sentido, se convierte en un principio de humanización escatológica y de anticipación y promesa de la nueva tierra y los nuevos cielos. Poseer el Espíritu significa comenzar a gozar de la plenitud humana escatológica, comenzar a vivir ya ahora la resurrección de modo simbólico-sacramental, pero real. No es casual que la resurrección de la carne y la vida eterna se sitúen en el tercer artículo del credo, en nuestra fe en el Espíritu.

Los signos de esta presencia del Espíritu en la historia tanto personal como universal y cósmica son siempre signos de vida, de amor, de solidaridad, de justicia, de misericordia, de gratuidad, de apertura a los demás, de alegría y gozo interno (Gal 5; 1 Cor 13). El Espíritu nos lleva a pasar de la exclusión a la inclusión, a reconocer las diferencias, a vivir una vida humilde y de abajamiento, de servicio, a vivir con lucidez y a ordenar nuestra vida, a ver a Dios en todo. En el fondo, el signo más claro de la presencia del Espíritu en nosotros

36. J. D. Zizioulas, Comunión y alteridad, óp. cit., p. 338. 
es ver si nos asemeja a la vida y opciones de Jesús de Nazaret ${ }^{37}$. En Jesús, en su misterio de cruz y resurrección, se disciernen los espíritus.

En este sentido, el Espíritu Santo es principio de humanización, de transfiguración de la humanidad y de toda la creación.

\section{A modo de conclusión}

Vivimos en un mundo profundamente polarizado y convulsionado no solo social y políticamente, sino también a nivel de pensamiento, de humanismos y de ideologías.

La sociedad del conocimiento, la globalización, el pluralismo cultural y religioso, el desastre ecológico, desafían profundamente a la humanidad de hoy. No solo estamos ante un cambio de época, sino que esta ya ha comenzado. No persisten ya los grandes ateísmos de los siglos XIX y XX, sino que vivimos en un momento mucho más light: indiferencia religiosa, agnosticismo, crítica a las instituciones religiosas, relativismo, idolatría del mercado y del consumo, narcisismo postmoderno del "carpe diem".

También en muchos cristianos se ha ido pasando del "Cristo sí, Iglesia no" al "Dios sí, Cristo no", para luego seguir afirmando "religión sí, Dios no". Y, finalmente, "religión no, espiritualidad sî" (J. B. Metz). Hay la sensación de que las instituciones religiosas, también la Iglesia, ahogan el Espíritu, deshumanizan, dividen y separan. Muchos buscan sinceramente una espiritualidad y una mística, sin religiones y sin dioses $^{38}$.

Existe una polarización entre una espiritualidad íntima, más o menos vaga y esotérica, y una fe cristiana histórica, vivida en comunidad eclesial. Hay también tensión entre divinización y humanización. Esto se traduce en la tensión entre una antropología pneumática y una antropología cristológica.

¿Hay una tensión irreductible entre humanización y divinización, entre Espíritu y Cristo, entre pluralismo religioso y pertenencia a la Iglesia de Jesucristo, entre mística y profecía histórica?

Sin Espíritu la vida humana está destinada a la muerte, la historia solo produce cadáveres, la creación se destruye y se consume lentamente. La misma vida cristiana sin Espíritu deviene moralismo, legalismo y autoritarismo en una Iglesia que no va más allá de ser una institución al lado de otros organismos humanos, culturales o financieros, una empresa que hace propaganda de su producto.

37. Cf. V. Codina, Una Iglesia Nazarena, Santander, 2010.

38. M. Corbí, Hacia una espiritualidad laica. Sin creencias, sin religiones, sin dioses, Barcelona, 2007. 
Desde la óptica del Espíritu, todas las afirmaciones de la antropología filosófica, de la sabiduría de los humanismos y de las religiones, pero también los asertos de la antropología teológica, sobre todo de una antropología cristológica, no quedan eliminados sino subsumidos. Si somos seres humanos y la vida tiene un sentido, si hemos sido creados en Cristo, si la vida cristiana es no solo imitación, sino seguimiento de Cristo, si los sacramentos nos configuran con Cristo en la Iglesia, si existe perdón de los pecados y liberación del poder del maligno, si por Cristo llegamos al Padre, si esperamos la resurrección de la carne y una tierra nueva, si tenemos vida divina y esperanza futura, todo ello es por el Espíritu, con el Espíritu y en el Espíritu, Espíritu que es el Espíritu de Jesús y del Padre, pero sin el cual no hay vida humana ni vida divina. En este sentido, la búsqueda actual de espiritualidad es algo legítimo y profundamente humano.

Pero esta antropología pneumatológica, que de algún modo puede ser aceptada por todos, para los cristianos desemboca necesariamente en una cristología pneumática y se abre a la Trinidad. Las dos manos del Padre, el Espíritu y el Hijo, en formulación de Ireneo, nos abrazan en la creación y nos conducen a la plenitud humana. No hay rivalidad ni competencia entre ellas, el Espíritu lleva a Cristo y Cristo nos comunica el Espíritu.

Es Jesús, el que ha nacido por obra del Espíritu y ha sido resucitado por el Espíritu, el que se ha convertido en nuevo Adán vivificante (1 Cor 15, 45), dador de vida, modelo de auténtica humanidad, el que a través del don del Espíritu nos humaniza verdaderamente al hacernos hermanos suyos e hijos del Padre. Entre divinización (theosis) y humanización no hay contradicción, sino que precisamente por Cristo y por el Espíritu somos verdaderamente humanos. El ser humano auténtico es ser en comunión con Dios, imagen de la Trinidad.

La gloria de Dios se manifiesta en la vida humana, pero esta vida no se agota en las coordenadas espacio-temporales de nuestra corta historia en este mundo, sino que, aunque muchos no sean conscientes de ello, gracias al Espíritu de Jesús, se abre al misterio eterno de la comunión trinitaria (GS 22). Tampoco debería haber contradicción entre Cristo e Iglesia, porque la Iglesia es la comunidad y el cuerpo de Cristo, aunque en realidad tengamos la experiencia de una Iglesia pecadora y muchas veces infiel al Señor. Solo el Espíritu de Jesús que actúa en la Iglesia y la santifica, a pesar de nuestros pecados, nos da la garantía de que en la Iglesia el Espíritu siempre tiene la última palabra y que la Iglesia, santa y pecadora, nunca será abandonada por el Espíritu del Señor.

En América Latina, la irrupción de los pobres, de los indígenas y afros, de las mujeres y los jóvenes en la sociedad y en la Iglesia, Medellín, las CEB, los obispos defensores de los pobres y verdaderos Santos Padres de la Iglesia latinoamericana, el florecimiento del diaconado permanente, la inserción de la vida religiosa entre los pobres, la teología de la liberación, la teología india, la teología feminista, la teología ecológica, los numerosos mártires, la fe del 
pueblo sencillo y pobre... son un signo claro de la presencia humanizadora, liberadora, vivificadora del Espíritu del Señor en nuestro continente y un llamado a defender la vida amenazada.

En realidad, como afirma Teresa de Lisieux al final de su vida y recoge Georges Bernanos en su Diario de un cura rural, todo es gracia, lo cual podemos traducir diciendo que todo es don y presencia del Espíritu vivificante, que con el Padre y el Hijo es juntamente adorado y glorificado. 